\title{
SISTEM PENERIMAAN PESANAN DAN PENJADWALAN PENGIRIMAN BARANG PT. ADVANCEDNET INDONESIA
}

\section{Eko Yuliardi}

Sekolah Tinggi Manajemen Informatika dan Komputer (STMIK) Muhammadiyah Jakarta, Indonesia

Email: yuliardieko11@gmail.com

\begin{tabular}{l}
\hline INFO ARTIKEL \\
\hline Diterima \\
10 Februari 2021 \\
Direvisi \\
21 Februari 2021 \\
Disetujui \\
15 Maret 2021
\end{tabular}

\section{Keywords:}

order acceptance system and order scheduling; PHP; $M Y S Q L$ and $U M L$.

\begin{abstract}
ABSTRACK
PT. Advancednet Indonesia is a growing company today, but in the activities of order acceptance and scheduling of delivery of goods still using manual means as well as in the process of input of order acceptance data and delivery scheduling using microsoft excel. Based on the above conditions the author aims to conduct research aimed at providing solutions to the problem through the assessment of various theories relevant to field study techniques, interviews and library studies. The author proposes a solution with a waterfall methodology approach consisting of, requirementa analysis, design, development, testing, and maintenance. As well as using PHP as a programming language and MySQL as a database, and Unified Modelling Language (UML) for its software design. The result of the development of this system is able to improve the system of order acceptance and scheduling of delivery of goods that have not been efficient. In accordance with the test results using the blackbox method, the test cases and results are carried out successfully and functionally can produce the expected output in terms of users and users contained in this system in the form of reports that can be printed out.
\end{abstract}

\begin{abstract}
ABSTRAK
PT. Advancednet indonesia adalah perusahan yang sedang berkembang saat ini, namun dalam kegiatan penerimaan pesanan dan penjadwalan pengiriman barang masih menggunakan cara manual seperti halnya dalam proses input data penerimaan pesanan dan penjadwalan pengiriman menggunakan microsoft excel. Berdasarkan kondisi diatas penulis melakukan penelitian yang bertujuan memberikan solusi terhadap permasalahan tersebut melalui
\end{abstract}


Kata Kunci :

sistem penerimaan pesanan dan penjadwalan pesanan; PHP; MYSQL dan UML. pengkajian berbagai teori yang relevan dengan teknik studi lapangan, wawancara dan studi pustaka. Penulis mengusulkan solusi dengan pendekatan metodologi waterfall yang terdiri dari, requirement Analisis, design, development, testing, dan maintenance. Serta menggunakan PHP sebagai bahasa pemrograman dan MySQL sebagai database, dan Unified Modelling Language (UML) untuk perancangan perangkat lunaknya. Hasil pengembangan sistem ini mampu memperbaiki siste $\mathrm{m}$ penerimaan pesanan dan penjadwalan pengiriman barang yang belum efesien. Sesuai dengan hasil pengujian menggunakan metode blackbox, kasus dan hasil uji coba dilakukan dengan sukses dan secara fungsional dapat menghasilkan output yang diharapkan dalam segi pengguna dan user yang terdapat didalam sistem ini berupa laporan yang dapat di print out.

Coresponden Author

Email: yuliardieko11@gmail.com Artikel dengan akses terbuka dibawah lisensi

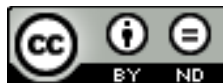

\section{Pendahuluan}

Era globalisasi membutuhkan informasi yang cepat dan akurat yang merupakan hal penting saat ini. Berbagai perusahaan berusaha mengembangkan bisnisnya dengan melakukan banyak perubahan menggunakan teknologi mutakhir seperti komputer yang menggantikan manusia, di mana komputer dapat mendukung perusahaan dalam pengambilan keputusan yang didukung oleh bagian penting dari teknologi informasi yaitu database. Basis data merupakan fungsi yang berperan sebagai tempat penyimpanan data, selain untuk mengelola sistem untuk menambah data baru, mengubah data, menghapus data, dan hubungan antar data yang disimpan, sehingga perusahaan dapat dengan mudah menggunakan data terstruktur saat dibutuhkan cepat dan akurat (Lubis, 2016).

PT. Advancednet Indonesia adalah anak perusahaan dari Advanced Network Solutions Sdn Bhd yang berpusat di Malaysia, dengan brand utama LITECH untuk kategori FTTH atau Fiber Optic Accessories, UTP Stuctured Cabling, Rack 19"server dan juga brand wolong untuk kategori produk batery. Perusahaan berdedikasi untuk melakukan proses peningkatan mutu dalam melaksanakan komitmen terhadap kualitas produk, memberikan pelayanan terbaik, dan berkesinambungan serta meningkatkan kualitas sumber daya manusia (SDM).

PT. Advancednet Indonesia merupakan perusahaan yang sedang berkembang dan bergerak dalam bidang penjualan meskipun di katakan perusahaan yang sedang 
berkembang dalam kesehariannya ada beberapa kegiatan yang dilakukan masih menggunakan sistem secara manual diantaranya penginputan data dan pembuatan laporan mengenai pesanan barang dan penjadwalan pengiriman barang yang dilakukan oleh setiap karyawan di masing-masing divisi menggunakan microsoft excel dilakukan dalam waktu bersamaan di akhir jam kerja. Hal tersebut tentu saja tidak efektif dan efesien karena penginputan tidak dilakukan secara langsung setelah tiap tahapan selesai sehingga data yang dihasilkan tidak up to date serta menimbulkan penundaan dan penumpukan penginputan. Penundaan penginputan juga akan memungkinkan terjadinya kesalahan input baik secara sengaja ataupun tidak disengaja. Oleh karena itu perlu adanya sistem yang bisa membantu perusahaan agar dalam kegiatan penerimaan pesanan dan penjadwalan pengiriman bisa berjalan secara sistematis, dengan adanya sistem penerimaan pesanan dan penjadwalan pengiriman.

Sistem definisi yang dikutip oleh Jacobs dalam pengantar sistem informasi adalah sekumpulan elemen yang terintegrasi dengan tujuan yang sama untuk mencapai tujuan (Putra \& Pramono, 2017). Sistem juga merupakan jaringan program yang saling berhubungan, dikelompokkan bersama untuk melakukan suatu aktivitas atau untuk tujuan tertentu. Sumber informasi adalah data yang merupakan data tunggal atau jamak. Data adalah kenyataan, menggambarkan apa yang terjadi pada saat tertentu (Hendrianto, 2013).

Ini mendefinisikan sistem informasi teknis sebagai rangkaian komponen yang saling berhubungan yang mengumpulkan dan mengambil, memproses, menyimpan, dan mendistribusikan informasi untuk mendukung pengambilan keputusan dan pengendalian perusahaan (Laudon \& Laudon, 2015). Menurut (Mikael et al., 2016) bahkan dalam keseharian kita sering menjumpai aktivitas pengiriman secara tidak langsung dalam banyak hal tanpa bantuan beberapa penyedia jasa transportasi, produsen sendiri tidak dapat menyelesaikan masalah pengiriman tersebut.

Manajemen logistik adalah bagian dari proses rantai pasokan, yang merencanakan, menerapkan, dan mengontrol efisiensi dan efektivitas penyimpanan dan aliran barang, jasa, dan informasi terkait sejak awal (point of origin) sampai titik konsumsi (point of consumption) dirancang untuk memenuhi kebutuhan pelanggan. Menurut (Rahmat, 2015), barang adalah produk berwujud (tangible) yang dapat diberikan kepada pembeli, melibatkan pengalihan kepemilikan dari penjual ke pelanggan.

Sistem informasi manajemen adalah sistem yang terintegrasi antara manusia dan mesin yang dapat memberikan informasi dengan cara yang mendukung fungsi operasi, manajemen, dan pengambilan keputusan di dalam organisasi (Rusdiana et al., 2014). Sistem menggunakan perangkat keras dan perangkat lunak (perangkat lunak dan perangkat keras), proses manual, model dan database untuk analisis perencanaan dan pengambilan keputusan. Menurut (Adam \& Yuliazmi, 2018) suatu sistem adalah kumpulan atau kumpulan elemen, komponen atau variabel yang diatur, berinteraksi satu sama lain, saling bergantung, dan terintegrasi. 


\section{Metode Penelitian}

Tempat penelitian dilaksanakan pada PT. Advancednet Indonesia yang beralamat di Komplek Prima Centre 1, Kedaung Kaliangke, Cengkareng, Jakarta Barat. Kecamatan cengkareng adalah wilayah yang terbilang cukup maju dan strategis, letaknya dekat dengan akses bandara Soekarno-Hatta dan juga pelabuhan Tanjung Priok sehingga banyak pabrik-pabrik dan komplek pergudangan yang beralamat di kecamatan ini.

Metode penelitian yang digunakan adalah metode pengumpulan data dengan menanyakan kepada koresponden, untuk memperoleh hasil wawancara, pemilik perusahaan membutuhkan suatu sistem informasi yang dapat mengelola data pesanan dari customer dan data penjadwalan pengiriman barang. Sehingga proses dari penerimaan pesanan sampai dengan penjadwalan pengiriman barang dapat dilakukan secara sistematis. Sistem informasi ini juga dimaksudkan agar tidak ada keterlambatan pengiriman kepada customer.

Tujuan Penelitian ini adalah mampu menghindari masalah mengenai kesalahan dalam pengiriman barang kepada customer, adanya sistem penjadwalan pengiriman barang diharapkan memudahkan dalam perencanaan pengiriman barang agar pengiriman tepat waktu sesuai dengan yang diharapkan oleh customer dan mampu membantu karyawan dalam melakukan kerjasama antar divisi dan menghindari kesalahan-kesalahan yang selama ini terjadi salah satunya penyiapan barang untuk kebutuhan customer tidak sesuai keinginan atau kebutuhan customer karena kurangnya komunikasi.

\section{Hasil dan Pembahasan}

Informasi adalah data yang diolah menjadi bentuk yang lebih berguna dan bermakna bagi penerimanya. Sumber informasi adalah data yang merupakan data tunggal atau jamak. Data adalah kenyataan, menggambarkan apa yang terjadi pada saat tertentu (Hendrianto, 2013). Menurut (Behlül et al., 2014): "Sistem informasi adalah serangkaian prosedur formal di mana data dikelompokkan, diproses menjadi informasi, dan didistribusikan kepada pengguna.

"Menurut (Dianty, 2016): "Sistem informasi adalah cara-cara yang diorganisasi untuk mengumpulkan, memasukan, dan mengolah serta menyimpan data, dan cara-cara yang diorganisasi untuk menyimpan, mengelola, mengendalikan, dan melaporkan informasi sedemikian rupa sehingga sebuah organisasi dapat mencapai tujuan yang telah ditetapkan." Menurut (SARI, 2018): "Sistem informasi, kadang-kadang disebut sistem pemrosesan data, adalah sistem buatan manusia, biasanya terdiri dari sekumpulan komponen (manual dan berbasis komputer) yang terintegrasi bersama untuk mengumpulkan, menyimpan dan mengelola data serta menyediakan saldo inventaris yang relevan." 
1. Perangkat Lunak dan Implementasi Sistem

a. PHP

PHP merupakan singkatan dari Hypertext Processor, yaitu suatu bahasa pemograman berbasis kode (script) yang digunakan untuk mengolah data dan mengirimkannya kembali ke web browser dan mengubahnya menjadi kode HTML (Jakaria \& Sentosa, 2019). Menurut (CALISTA, 2015) Dia berkata: "PHP adalah pemrograman interpreter, yaitu proses mengubah sebaris kode menjadi kode mesin yang dapat langsung dipahami oleh komputer saat menjalankan sebaris kode."

b. PHP Native

Native PHP merupakan kombinasi pemrograman web dari bahasa pemrograman berbasis bahasa pemrograman PHP, yang dapat disisipkan melalui teks Javascript, CSS, Bootstrap, dll.

c. MySQL

Menurut Hidayatullah, (CLAUDIA, 2019) :" MySQL adalah salah satu aplilaksi DBMS yang sudah banyak digunakan oleh para pemrogram aplikasi web". Pertama MySQL dikembangkan oleh MySQL AB yang kemudian di akuisisi sun microsystem dan terakhir MySQL dikelola oleh Oracle Coorporation (Nisa, 2015).

d. XAMPP

XAMPP adalah perangkat lunak yang dikembangkan dari LAMP, proyek nirlaba yang dikembangkan oleh Apache Friends, termasuk beberapa perangkat lunak (Linux, Apache, MySQL, PHP dan PERL, dll.)

e. Hyper Text Markup Language (HTML)

Hypertext Markup Language (HTML) adalah bahasa yang digunakan untuk membuat halaman web Internet dan format hypertext sederhana yang ditulis dalam file berformat ASCII untuk menghasilkan bentuk tampilan yang terintegrasi.

f. Cascading Style Sheet (CSS)

Style sheet bertingkat adalah salah satu bahasa pemrograman web standar. Style sheet adalah fungsi yang sangat penting untuk membuat HTML dinamis. Style sheet adalah tempat anda dapat mengontrol dan mengatur gaya yang ada. Style sheet menjelaskan tampilan dokumen HTML di layar.

g. Bootstrap

Bootstarp ini adalah pustaka kerangka kerja CSS yang khusus dibuat untuk bagian pengembangan front-end situs web. Bootstrap adalah framework atau alat untuk membuat aplikasi web atau situs web yang responsif dengan cepat, mudah, dan gratis. Bootstrap terdiri dari CSS dan HTML, digunakan untuk menghasilkan kisi, tata letak, tipografi, tabel, formulir, navigasi, dan lainnya. 


\section{h. JavaScript}

JavaScript menurut (Lidya et al., 2015) merupakan bahasa pemrograman komputer yang dinamis. Umumnya biasanya digunakan pada web browser untuk membuat halaman web interaktif yang menarik dan mengimplementasikan berbagai fungsi pada halaman web tersebut. JavaScript merupakan salah satu pemrograman web yang harus kita pelajari (kecuali HTML dan CSS).

2. Input Penerimaan Pesanan

Aktor: Sales

Menu: Pesanan

Tampilan menu pesanan adalah tampilan input penerimaan pesanan, dimana menu ini berfungsi untuk menambah data penerimaan pesanan baru
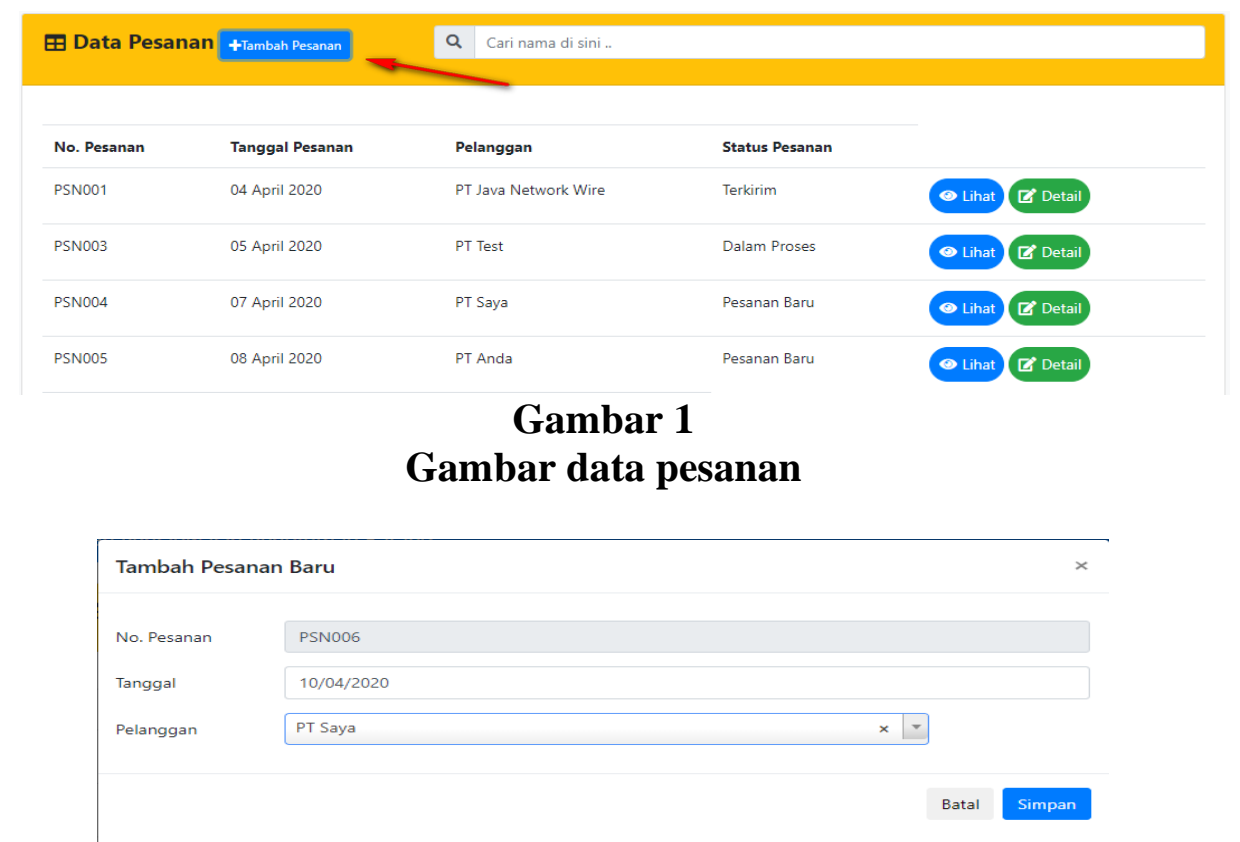

\section{Gambar 2}

Form tambah penerimaan pesanan

1) No pesanan terisi otomatis,

2) Memilih tanggal,

3) Memilih pelanggan dengan mengetik namanya akan muncul nama pelanggan sesuai yang diketik/cari. Jika belum ada silakan tambahkan data pelanggan pada menu Data Master -> Pelanggan.

4) Klik Simpan.

KLIK Tombol Detail sesuai no. pesanan yang baru diinput untuk melengkapi detail pesanan. 
Sistem Penerimaan Pesanan dan Penjadwalan Pengiriman Barang PT. Advancednet Indonesia

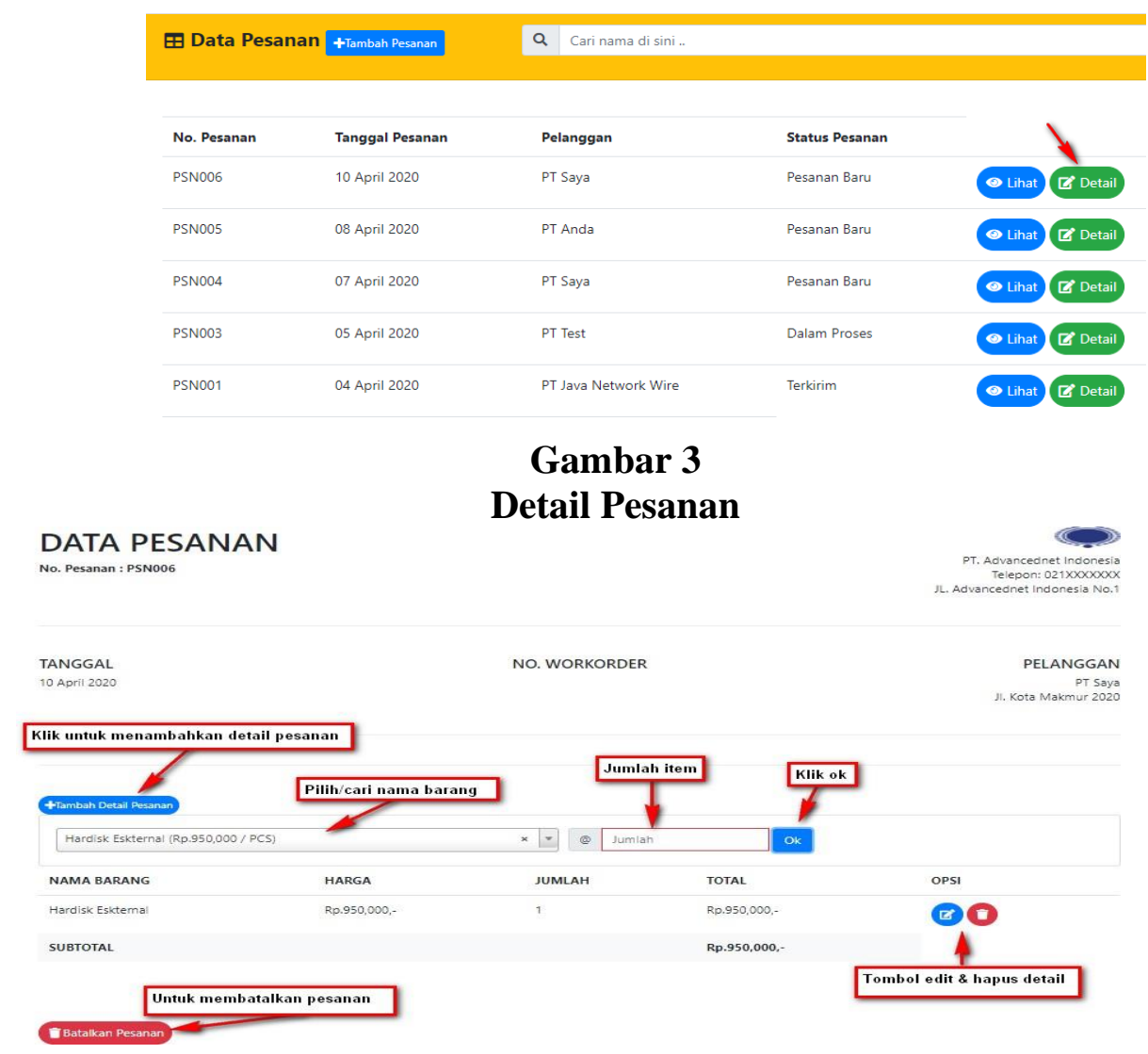

Gambar 4

Form Detail Pesanan

Tombol lihat untuk melihat data detail pesanan yang sudah tersimpan

3. Create Work Order (Membuat WO)

Aktor : Admin

Gudang Menu : Pesanan

Lihat data pesanan berstatus "Pesanan Baru"

\begin{tabular}{|c|c|c|c|c|}
\hline \multicolumn{2}{|c|}{ 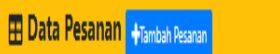 } & \multicolumn{3}{|l|}{ Q. Cri nam o o sini. } \\
\hline \multirow[b]{2}{*}{ No. Pessanan } & \multirow[b]{2}{*}{ Tanggal Pessnan } & \multirow[b]{2}{*}{ Pelarggan } & \multirow[b]{2}{*}{ Status Pesanan } & Klik unituk ninethilhat dettil \\
\hline & & & & \\
\hline P35006 & 10 Apri 2020 & PTSaja & Pessinan 8aru & \\
\hline PSNOOS & OB Apri 2220 & PTAnod & Pegran 88a & \\
\hline
\end{tabular}

Gambar 5

Data yang akan dibuatkan Work Order 
Eko Yuliardi

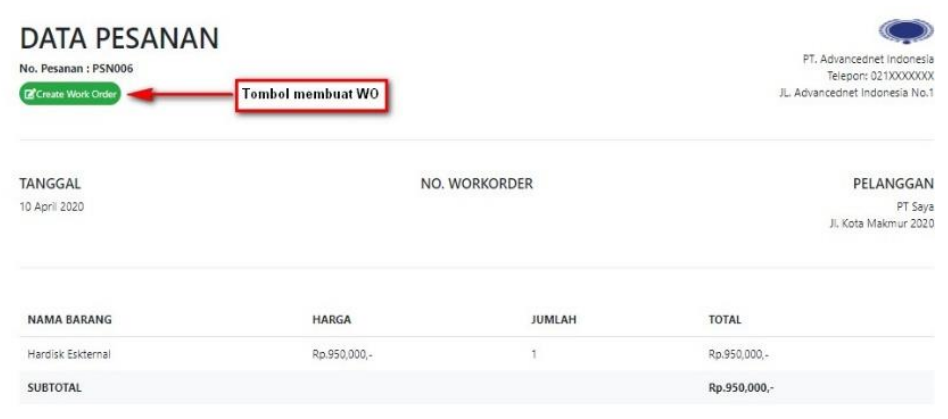

Gambar 6

Create Work Order

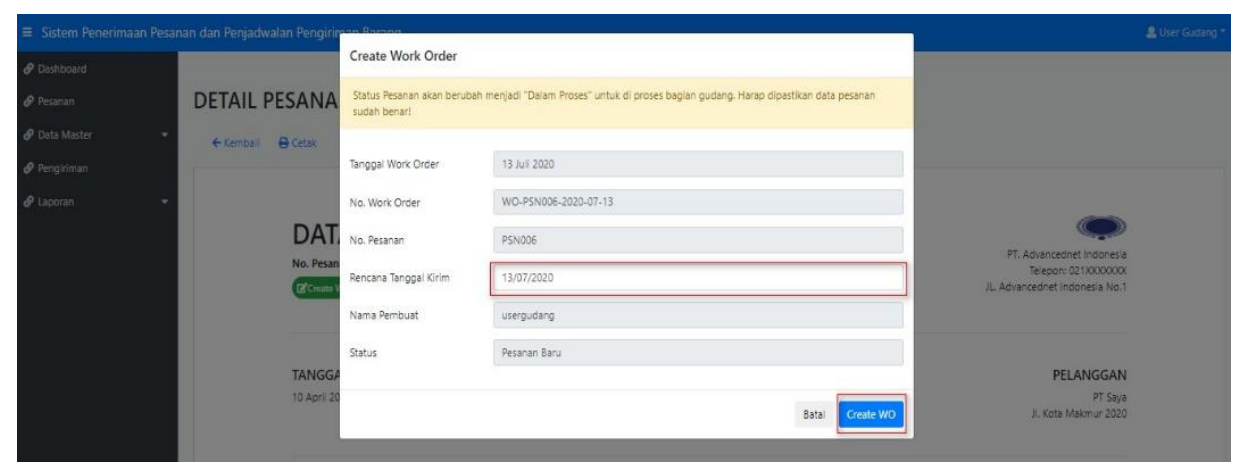

Gambar 7

Form input Work Order

1) Isi tanggal rencana pengiriman, yang lainnya dibiarkan saja

2) Klik Create Wo

3) Status pesanan akan berubah menjadi "Dalam Proses"

4) Nomor work order telah dibuat

4. Packing Barang

1) Selanjutnya persiapan dan packing barang oleh staff gudang

2) Staff gudang mengkonfirmasi kepada admin gudang bahwa barang sudah siap dikirim

5. Konfirmasi siap dikirim

Aktor: Admin Gudang

Menu : Pesanan

Setelah dikonfirmasikan oleh bagian packing bahwa barang sudah siap dikirim maka admin gudang kembali membuka data pesanan sesuai dengan nomor pesanan dan nomor work order yang dikonfirmasikan sudah siap dikirim. 
Sistem Penerimaan Pesanan dan Penjadwalan Pengiriman Barang PT. Advancednet Indonesia

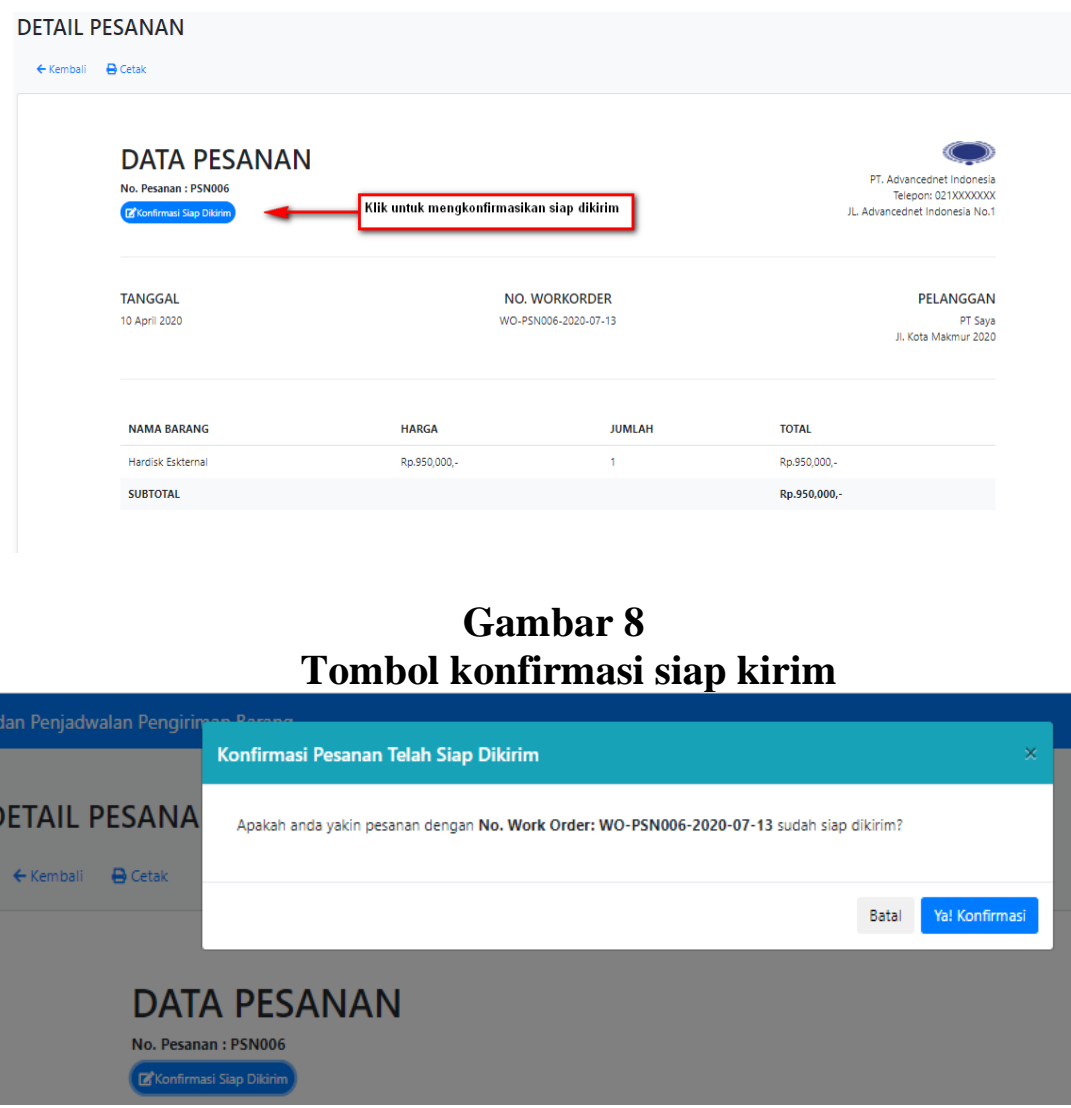

\section{Gambar 9}

Form konfirmasi siap kirim

6. Pengiriman

Aktor : Logistik

Menu: Pengiriman

Buka menu Pengiriman atau klik Quick Menu siap dikirim

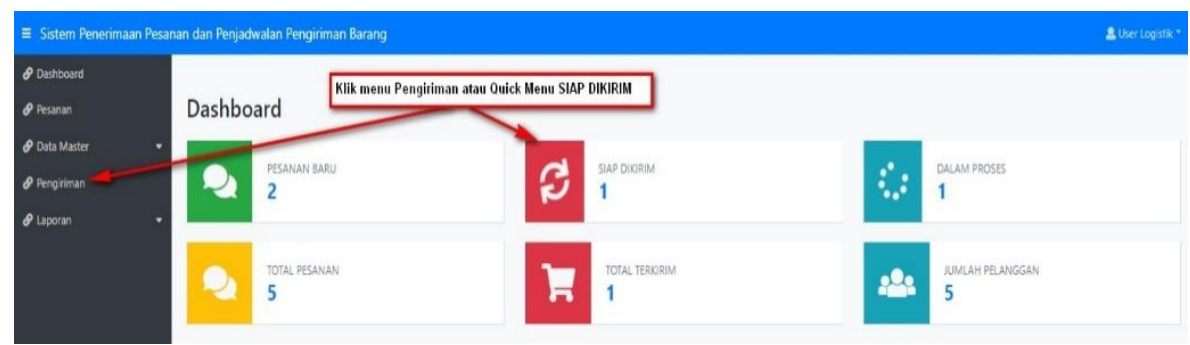

Gambar 10

Halaman Dashboard Menu 


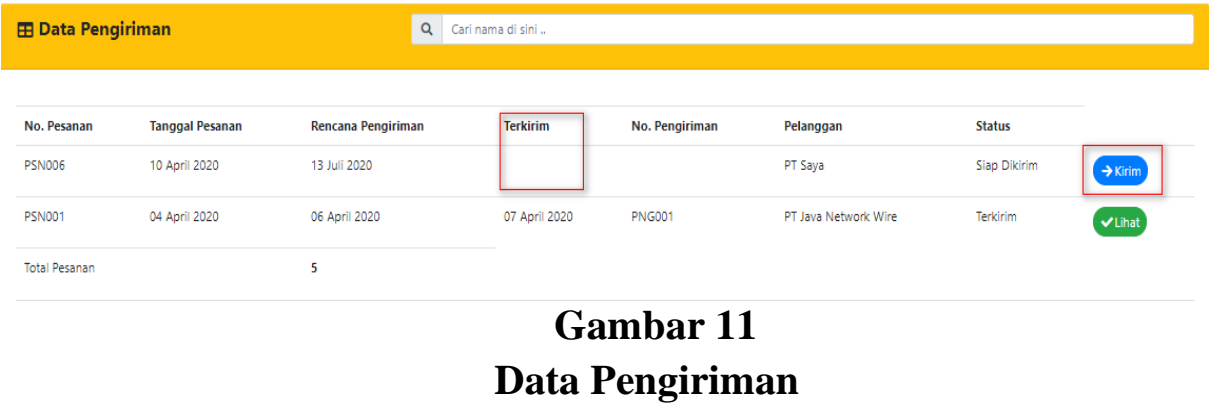

1) Sampai disini user logistik/manager logistik perlu menjadwalkan tanggal pengiriman pada data yang berstatus siap dikirim.

2) Selanjutnya klik kirim jika sudah dijadwalkan tanggal pengirimannya maka akan muncul form berikut

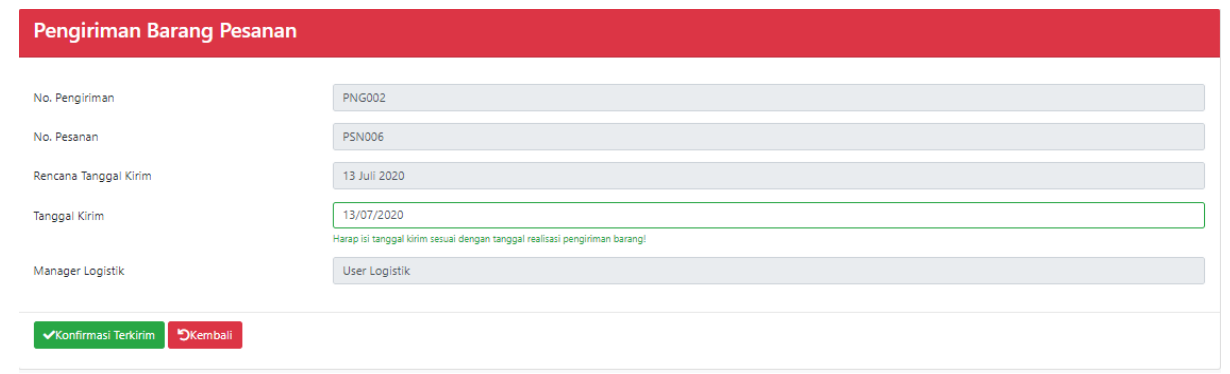

\section{Gambar 12}

Form pengiriman

7. Testing

Tabel 1

Tabel Pengujian Login

Hasil Uji Coba Login

\begin{tabular}{cccc}
\hline Pengujian & $\begin{array}{c}\text { Detail } \\
\text { Pengujian }\end{array}$ & Yang Diharapkan & Hasil \\
\hline Login & $\begin{array}{c}\text { Memasukan } \\
\text { Username }\end{array}$ & $\begin{array}{c}\text { Sistem akan } \\
\text { masuk ke halaman } \\
\text { dasboard member }\end{array}$ & berhasil \\
\hline
\end{tabular}

Tabel 2

Tabel Penginputan Pesanan

Hasil Uji Input Pesanan

\begin{tabular}{cccc}
\hline Pengujian & Detail Pengujian & Yang Diharapkan & Hasil \\
\hline Login & $\begin{array}{c}\text { Memasukan } \\
\text { Username }\end{array}$ & $\begin{array}{c}\text { Sistem akan } \\
\text { masuk ke halaman } \\
\text { dasboard member }\end{array}$ & berhasil \\
\hline Dasboard & $\begin{array}{c}\text { Masuk menu } \\
\text { pesanan, Input } \\
\text { data pesanan }\end{array}$ & $\begin{array}{c}\text { Sistem akan menyimpan } \\
\text { data } \\
\text { pesanan }\end{array}$ & berhasil \\
\hline
\end{tabular}


Sistem Penerimaan Pesanan dan Penjadwalan Pengiriman Barang PT. Advancednet Indonesia

\section{Tabel 3}

Tabel Pembuatan Work Orde

Hasil Uji Work Order

\begin{tabular}{cccc}
\hline Pengujian & Detail Pengujian & Yang Diharapkan & Hasil \\
\hline Login & Memasukan & $\begin{array}{c}\text { Sistem akan masuk } \\
\text { ksername halaman } \\
\text { dasboard }\end{array}$ & berhasil \\
Dasboard & $\begin{array}{c}\text { Lihat data pesanan } \\
\text { Membuat Work } \\
\text { Order }\end{array}$ & $\begin{array}{c}\text { Sistem akan } \\
\text { menyimpan data } \\
\text { Work } \text { order }\end{array}$ & berhasil \\
\hline
\end{tabular}

Tabel 4

Tabel Pengiriman Barang

\begin{tabular}{cccc}
\hline & \multicolumn{2}{c}{ Hasil Uji Work Order } \\
\hline Pengujian & Detail Pengujian & Yang Diharapkan & Hasil \\
\hline Login & Memasan & Sistem akan masuk ke & berhasil \\
& Username & halaman \\
& dasboard & \\
Dasboard & Lihat data barang siap & Sistem akan menghapus \\
& kirim , kirim & data pesanan yang & berhasil \\
& & sudah terkirim & \\
\end{tabular}

\section{Maintenace}

Perawatan sistem biasa dilakukan oleh admin. Perawatan tersebut dapat dilakukkan secara berkala yakni setiap 3 bulan, 6 bulan atau bahkan satu tahun atau juga dapat disesuaikan dengan berjalanya sistem.

Berikut kualitas dari informasi yang umumnya digunakan sebagai acuan:

a. Akurat

Akurat disini maksudnya adalah informasi yang di dapat harus bebas dari kesalahan, tidak menyesatkan, tidak ada perkiraan atas informasi yang di dapat. Maksud dari perkiraan diatas adalah, misal seseorang membutuhkan informasi atas jawaban dari pertanyaanya dan membutuhkan satu jawaban tepat, maka hasil yang di dapatkan juga harus berupa jawaban yang tepat bukan jawaban kurang dari nilai yang diharapkan atau lebih dari itu.

b. Tepat Waktu

Setiap informasi yang diinginkan, biasanya berhubungan dengan ketepatan waktu yang ada. Sebuah informasi yang diterima melebihi dari waktu yang ditentukan biasanya akan menjadi sebuah informasi yang kedaluarsa dan tidak berguna sehingga menyebabkan operasional yang ada terganggu. Sehingga diperlukanlah ketepatan waktu atas jawaban dari setiap permintaan informasi yang ada. 
c. Relevan

Relevan disini maksudnya adalah informasi yang diberikan kepada user yang sedang mencari informasi adalah benar-benar informasi yang dibutuhkan. Jadi misalkan seorang akuntan sedang mencari informasi tentang bagaimana rumus neraca, maka yang ditampilkan adalah rumus dari neraca yang dimaksud, bukan rumus persamaan pythagoras atau rumus persamaan atom kimia.

d. Tepat Waktu

Setiap informasi yang diinginkan, biasanya berhubungan dengan ketepatan waktu yang ada. Sebuah informasi yang diterima melebihi dari waktu yang ditentukan biasanya akan menjadi sebuah informasi yang kedaluarsa dan tidak berguna sehhingga menyebabkan operasional yang ada terganggu. Sehingga diperlukanlah ketepatan waktu atas jawaban dari setiap permintaan informasi.

Internet atau jaringan interkoneksi adalah sistem komunikasi global yang menghubungkan komputer global dan jaringan komputer. Setiap komputer dan jaringan terhubung secara langsung atau tidak langsung ke beberapa jalur utama yang disebut tulang punggung internet. Tujuan internet adalah untuk memaksimalkan interoperabilitas, yaitu untuk memaksimalkan kemampuan program pada sistem komputer jaringan yang berbeda untuk berkomunikasi secara andal (Alam, 2015). Karena adanya komponen perangkat keras dan perangkat lunak tertentu, pengguna internet dapat saling berinteraksi. Komputer dengan berbagai platform dan jaringan menggunakan sistem operasi yang berbeda dengan karakteristiknya sendiri (Unix, Linux, Windows, Mac, dll.) untuk bertukar informasi melalui protokol. Perjanjian tersebut menentukan cara komputer dapat berkomunikasi dengan komputer lain.

\section{Kesimpulan}

Pembuatan sistem informasi penerimaan pesanan dan penjadwalan pengiriman barang PT. Advancednet Indonesia bertujuan untuk mempermudah pekerjaan admin gudang, warehouse, dan juga divisi logistik dalam menangani proses penerimaan pesanan dan pengiriman barang kepada customer secara tepat dan cepat. Berdasarkan hasil penelitian yang dilakukan penulis di PT. Indonesia Advanccednet telah membentuk sistem informasi penerimaan pesanan dan pengaturan pengiriman barang, maka dapat diambil kesimpulan bahwa penerapan sistem yang baru untuk menggantikan proses manual sangat menunjang terhadap proses pekerjaan pada tiap divisi, sehingga kebutuhan informasi dapat terpenuhi secara cepat tepat dan up to date, pengolahan data dengan sistem yang baru mempermudah dalam monitoring status stok barang, sistem memberikan kemudahan dalam memonitoring status pesanan dan juga mempermudah dalam melakukan penjadwalan pengiriman barang. 


\section{BIBLIOGRAFI}

adam, F. N., \& Yuliazmi, Y. (2018). Analisa Dan Perancangan Sistem Informasi Pengadaan Bahan Baku Dengan Model Electronic Supply Chain Management (EScm) Pada Pt. Hassana Boga Sejahtera Guna Mengatasi Keterlambatan Produksi. Idealis: Indonesia Journal Information System, 1(1), 99-105.

Alam, L. (2015). Influinsasi Media Internet Terhadap Proses Pemilu Di Indonesia. Seminar Nasional Informatika (Semnasif), 1(6).

Behlül, B., Ayfer, S., Sezgin, V., Altay, K., Mustafa, Ç., Cem, Ç., Bilge, Ö., Fatih, A., Emrah, A., \& Zafer, B. (2014). Safety Of Endoscopic Retrograde Cholangiopancreatography In Patients 80 Years Of Age And Older. Przeglad Gastroenterologiczny, 9(4), 227.

Calista, B. (2015). Aplikasi Pengolahan Data Pemesanan Barang Pada Cv Fitrana Palembang. Politeknik Negeri Sriwijaya.

Claudia, B. (2019). Aplikasi Pengolahan Data Peserta Pendidikan Dan Pelatihan Pada Pt. Jitu Kreasi Utama Berbasis Website. Politeknik Negeri Sriwijaya.

Dianty, A. (2016). Perancangan Sistem Informasi Akuntansi Penggajian Berbasis Komputer Pada Pt Ladang Makmur. Politeknik Negeri Sriwijaya.

Hendrianto, D. E. (2013). Pembuatan Sistem Informasi Perpustakaan Berbasis Website Pada Sekolah Menegah Pertama Negeri 1 Donorojo Kabupaten Pacitan. IjnsIndonesian Journal On Networking And Security, 4(3).

Jakaria, D. A., \& Sentosa, Y. B. (2019). Sistem Informasi Penjualan Barang Pada Toko Bangunan Sribayu Berbasis Web. Jurnal Manajemen Dan Teknik Informatika (Jumantaka), 3(1).

Laudon, K. C., \& Laudon, J. P. (2015). Management Information Systems. Pearson Upper Saddle River.

Lidya, S. K., Sitompul, O. S., \& Efendi, S. (2015). Sentiment Analysis Pada Teks Bahasa Indonesia Menggunakan Support Vector Machine (Svm) Dan K-Nearest Neighbor (K-Nn). Seminar Nasional Teknologi Informasi Dan Komunikasi, 1-8.

Lubis, A. (2016). Basis Data Dasar. Deepublish.

Mikael, R., Ann-Christine, F., Lars, L., \& Rikard, S. (2016). Variation Analysis Considering Manual Assembly Complexity In A Cat Tool. Procedia Cirp, 43, 9499.

Nisa, K. (2015). Perancangan Website Desa Wisata Karangrejo Sebagai Media Informasi Dan Promosi. Bianglala Informatika, 3(1). 
Eko Yuliardi

Putra, I. N., \& Pramono, S. H. (2017). Konsepsi Pembangunan Kekuatan Dan Kemampuan Sistem Informasi Operasi Tni Al Dalam Mendukung Penyelenggaraan Strategi Pertahanan Laut Nusantara. Journal Asro-SttalInternational Journal, 7, 1-48.

Rahmat, R. (2015). Analisis Sistem Informasi Akuntansi Pembelian Kredit Spare Part Pt. Lili Indah Prima Karya. Akmen Jurnal Ilmiah, 12(3).

Rusdiana, A., Irfan, M., \& Irfan, M. (2014). Sistem Informasi Manajemen. Pustaka Setia.

Sari, M. D. F. (2018). Pengaruh Kualitas Sistem Informasi Akuntansi Dan Kinerja Karyawan Terhadap Keefektifan Pengendalian Internal Perusahaan. Universitas Muhammadiyah Gresik. 